Sherris, J. C., Shoesmith, J. G., Parker, M. T. \& Breckon, D. (1959). J. gen. Microbiol. 21, 389-396

\title{
Tests for the Rapid Breakdown of Arginine by Bacteria: Their Use in the Identification of Pseudomonads
}

\author{
By J. C. SHERRIS* AND J. G. SHOESMITH \\ Department of Bacteriology, University of Manchester \\ AND M. T. PARKER AND D. BRECKON \\ Public Health Laboratory, Manchester, 10
}

SUMMARY : Cultures of 351 miscellaneous Gram-negative rods including 54 pseudomonads were tested for their capacity to break down arginine rapidly by Møller's qualitative technique, by a new qualitative method, and by a quantitative technique which uses standardized washed suspensions. All but 5 of the pseudomonads gave positive results by both qualitative techniques. Among the other organisms tested, positive results were given by Aeromonas strains, some Cloacs strains, some Salmonellas, and, in the case of the new qualitative technique, by 5 strains among other groups. With the quantitative technique $50 \%$ of the arginine was broken down in $2 \mathrm{hr}$. by all but one of the pseudomonads as compared with only four strains among the other groups. The arginine was broken down completely by 49 of the 54 pseudomonads, but by no other organisms. The ability to break down arginine rapidly is a useful taxonomic feature for pseudomonads and the qualitative tests may have practical value in the identification of strains which do not produce pigment.

During 1958 two concurrent and independent investigations were being made in our laboratories. One concerned the value of tests for amino acid breakdown in the classification of Gram-negative bacilli, and the other was designed to determine whether the phenomenon of arginine-activated motility was limited to pseudomonads (Sherris, Preston \& Shoesmith, 1957). The results of these investigations led us to the conclusion that the possession of a potent arginase might be a characteristic useful for the identification of pseudomonads. Further collaborative experiments were therefore made to correlate our findings and to extend the number and variety of the organisms tested. The results of these investigations form the basis of the present communication.

\section{METHODS}

Organisms. The strains investigated were all Gram-negative rods. They belonged to a wide variety of genera and species and consisted partly of named cultures from the collection of the Manchester University Department of Bacteriology, the National Collection of Type Cultures, and the National Collection of Plant Pathogens, and partly of strains isolated at the Public Health Laboratory from human material. The strains from the culture collections were accepted as representative of the genera and species to which they

\footnotetext{
* Present address : Microbiology Laboratory, Teaching Hospital, University of Washington, Seattle 5 .
} 
had been allocated, and the identity of the freshly-isolated strains was determined as far as possible by morphological, cultural, biochemical and serological examination. All strains classified as pseudomonads were polar flagellate, produced acid from glucose only or no acid from any carbohydrate in $1 \%$ peptone water and were strongly oxidase-positive (Gordon \& McLeod, 1928; Kovacs, 1956). Most strains also produced blue or green water-soluble pigments and were cytochrome oxidase-positive (Gaby \& Hadley, 1957). All but six of the strains were strongly catalase-positive and all but three were insensitive to Erythromycin as judged by absence of inhibition zones around tablets containing $10 \mu \mathrm{g}$. of the antibiotic.

\section{Tests for arginine breakdown}

All the strains studied were tested for ability to break down arginine by two qualitative techniques, and some also by a quantitative method.

The qualitative method of Møller (1955). Medium containing (wt./l.): Evans' peptone, 5 g.; Lab Lemco, 5 g.; pyridoxal, 0.005 g.; glucose, 0.5 g.; L-arginine monohydrochloride, $10 \mathrm{~g}$.; bromcresol purple, $0.01 \mathrm{~g}$., and cresol red, 0.005 g., adjusted to $\mathrm{pH} 6.0$, was distributed in narrow tubes to give columns $2 \mathrm{~cm}$. in height. After autoclaving (10 lb./sq.in. for $10 \mathrm{~min}$.), the tubes were sealed with sterile liquid paraffin. A tube of this medium and a control without arginine were inoculated with a straight wire from a nutrient agar culture. Organisms which produced acid from glucose under the conditions of the test rapidly turned the control tube yellow, and those which did not attack arginine also gave a yellow colour in the arginine-containing medium. With organisms, such as pseudomonads, which did not produce acid from glucose in Møller's medium, the control tube remained slate-grey in colour for the first 1-2 days, and sometimes became faintly mauve on further incubation. Arginine breakdown was indicated by the appearance of a violet colour in the tube containing the test medium.

All tests on members of the Enterobacteriaceae were carried out only at $37^{\circ}$; other organisms were tested at $22^{\circ}$ and also at $37^{\circ}$. Tubes were examined daily for 5 days. A definite violet colour in the test medium with a yellow, slate-grey or faintly mauve colour in the control tube was taken as evidence of arginine breakdown. After incubation for 4 days the tubes were tested for ammonia with Nessler's reagent as described by Møller (1955).

The Manchester qualitative technique. The workers in the University Department of Bacteriology developed a qualitative test for arginine breakdown, using a medium modified from that described for urease tests by Christensen (1946). It consisted of: peptone (Evans), $1.0 \mathrm{~g}$; $\mathrm{NaCl}, 5.0 \mathrm{~g}$.; $\mathrm{KH}_{2} \mathrm{PO}_{4}$ (anhydrous), $2.0 \mathrm{~g}$.; phenol red, $2.5 \mathrm{ml}$. of a $0.4 \%(\mathrm{w} / \mathrm{v})$ solution in water; distilled water to 1 litre. The $\mathrm{pH}$ value was adjusted to $6 \cdot 8$, and glucose $(1 \cdot 0 \mathrm{~g}$.) and L-arginine monohydrochloride $(10.0 \mathrm{~g}$.) were added. The medium was distributed in $5 \mathrm{ml}$. amounts in $14 \mathrm{~mm}$. diameter tubes, and autoclaved at $10 \mathrm{lb} . / \mathrm{sq}$. in. for $10 \mathrm{~min}$. Two drops $(c .0 .04 \mathrm{ml}$.) of a 24-hr. peptone water culture were inoculated into a tube of this medium and into a control without added arginine. The tubes were incubated for $24 \mathrm{hr}$., in most instances at 
$37^{\circ}$, but tests on organisms with a lower optimum growth temperature were carried out at $30^{\circ}$ or $22^{\circ}$, whichever was appropriate. The colour which developed after incubation was compared visually with that given by buffer solutions of $\mathrm{pH} 7 \cdot 0,7 \cdot 4,8.0$ and $8 \cdot 4$ containing the same concentration of phenol red as the medium.

The duration of this test and the conditions to be used were determined after preliminary experiments had shown that many organisms, notably strains of Salmonella and Escherichia, produced an alkaline reaction when the time of incubation exceeded $24 \mathrm{hr}$. Others, such as Achromobacter anitratus (Bacterium anitratum), would break down arginine under the relatively aerobic conditions obtaining on the surface of a sloped agar-containing medium, but not under the reducing conditions which developed in a deep fluid medium. Breakdown of arginine by pseudomonads, on the other hand, occurred under relatively anaerobic conditions and depended in fluid media on sedimentation of organisms from the area of active growth at the surface. The conditions for arginine breakdown by these strains thus resembled those previously described for Pseudomonas viscosa (Sherris et al. 1957).

The quantitative arginase reaction. Since the results of the qualitative tests depended on the rate of growth in the test media as well as on the enzymic activity of the organisms, the ability of washed suspensions of organisms to break down arginine under defined conditions was investigated. The organisms investigated included those which gave a positive reaction in 24 $\mathrm{hr}$. by Møller's technique, those which gave a colour change equivalent to $\mathrm{pH} 7 \cdot 4$ by the Manchester qualitative method, representative samples of each of the genera studied, and all strains of uncertain taxonomic position. Among the salmonellas, however, only the strains which showed the greatest activity against arginine by the Manchester technique were tested. These strains were all positive by Møller's method.

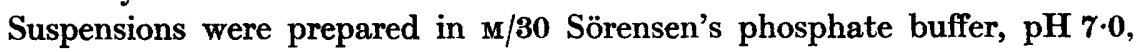
from overnight nutrient agar plate cultures. The organisms were washed once and resuspended to an opacity equivalent to Brown's tube No. 10 (equivalent to four times the International Standard of Opacity). Suspension (2 ml.) was mixed in $14 \mathrm{~mm}$. diameter tubes with $2 \mathrm{ml}$. of mM-L-arginine monohydrochloride in $\mathrm{M} / 30$ buffer, and incubated at $37^{\circ}$ for $2 \mathrm{hr}$. A control tube with buffer in place of the arginine solution was treated similarly. Samples $(1 \mathrm{ml}$.) were removed after incubation for 30 and 120 minutes and the organisms lysed by adding $1 \mathrm{ml}$. of $3 \mathrm{~N}-\mathrm{NaOH}$. The arginine present was estimated by adding the $\alpha$-naphthol reagent of Rosenberg, Ennor \& Morrison (1956) and measuring the intensity of the colour formed in a Hilger 'Biochem' absorptiometer.

\section{RESULTS}

The distribution according to genera or groups of the $\mathbf{3 5 1}$ strains investigated, and the results obtained, are shown in Table 1. The pseudomonads comprised: 28 strains of Pseudomonas aeruginosa; 14 strains of $P$. fuorescens; one strain each of $\boldsymbol{P}$. graveolens, $\boldsymbol{P}$. mucidolens, $\boldsymbol{P}$. ovalis, $\boldsymbol{P}$. polycolor, $\boldsymbol{P}$. aeruginosa var. erythrogenes and $\boldsymbol{P}$. viscosa; 6 non-pigmented unclassified strains. A positive 
result by Møller's technique denotes the development of an alkaline reaction as shown by the production of a definite $\mathrm{pH}$ indicator change after $24 \mathrm{hr}$. incubation either at $37^{\circ}$ or at $22^{\circ}$. A positive result by the Manchester qualitative technique was taken as the development of a colour change equivalent to $\mathrm{pH} \mathrm{8.0}$ or greater after $24 \mathrm{hr}$. incubation. A positive reaction by the quantitative technique was taken as the breakdown of over $50 \%$ of the arginine in $2 \mathrm{hr}$.

Table 1. Results of tests for arginine breakdown by different bacteria

\begin{tabular}{|c|c|c|c|c|c|c|c|c|}
\hline \multirow[b]{2}{*}{$\begin{array}{c}\text { Genera or } \\
\text { groups }\end{array}$} & \multirow[b]{2}{*}{$\begin{array}{l}\text { No. of } \\
\text { strains }\end{array}$} & \multicolumn{2}{|c|}{$\begin{array}{l}\text { Møller's } \\
\text { technique }\end{array}$} & \multicolumn{2}{|c|}{$\begin{array}{l}\text { Manchester } \\
\text { technique }\end{array}$} & \multicolumn{3}{|c|}{ Quantitative technique } \\
\hline & & $\begin{array}{l}\text { Positi } \\
\text { at 24 h }\end{array}$ & $\begin{array}{l}\text { Negative } \\
\text { at } 24 \mathrm{hr} \text {. }\end{array}$ & $\begin{array}{l}\text { Positi } \\
\text { at } 241\end{array}$ & $\begin{array}{l}\text { gative } \\
24 \mathrm{hr} \text {. }\end{array}$ & Positi & gative & $\begin{array}{c}\text { Not } \\
\text { tested }\end{array}$ \\
\hline Escherichia & 60 & $\mathbf{0}$ & 60 & 1 & $\mathbf{5 9}$ & $\mathbf{0}$ & 10 & 50 \\
\hline Shigella & 21 & $\mathbf{0}$ & 21 & $\mathbf{0}$ & 21 & $\mathbf{0}$ & 6 & 15 \\
\hline Klebsiella & 28 & $\mathbf{0}$ & 28 & $\mathbf{0}$ & 28 & $\mathbf{0}$ & 7 & 21 \\
\hline Cloaca & 19 & 7 & 12 & 6 & 18 & $\mathbf{0}$ & 8 & 11 \\
\hline Serratia & $\boldsymbol{9}$ & $\mathbf{0}$ & $\mathbf{9}$ & $\mathbf{0}$ & $\mathbf{9}$ & $\mathbf{0}$ & 4 & 5 \\
\hline Citrobacter & 10 & 0 & 10 & $\mathbf{0}$ & 10 & $\mathbf{0}$ & 6 & 4 \\
\hline Salmonella & 28 & 24 & 4 & $\mathbf{5}$ & 28 & $\mathbf{0}$ & $\boldsymbol{\theta}$ & 19 \\
\hline Hafnia & $\mathbf{1}$ & $\mathbf{0}$ & 1 & $\mathbf{0}$ & 1 & $\mathbf{0}$ & 1 & $\mathbf{0}$ \\
\hline Proteus & 29 & 0 & 29 & 0 & 29 & $\mathbf{0}$ & $\boldsymbol{\theta}$ & 20 \\
\hline Providence & 1 & 0 & 1 & $\mathbf{0}$ & 1 & $\mathbf{0}$ & 1 & 0 \\
\hline Pasteurella & $\mathbf{3}$ & $\mathbf{0}$ & $\mathbf{3}$ & $\mathbf{0}$ & $\mathbf{8}$ & $\mathbf{0}$ & 3 & $\mathbf{0}$ \\
\hline Bordetella & $\mathbf{3}$ & 0 & $\mathbf{3}$ & $\mathbf{0}$ & $\mathbf{3}$ & $\mathbf{0}$ & 2 & 1 \\
\hline $\begin{array}{l}\text { Achromobacter } \\
\text { anitratus (Bact. } \\
\text { anitratum) }\end{array}$ & 40 & 0 & 40 & 8 & 87 & $\mathbf{0}$ & 25 & 15 \\
\hline $\begin{array}{l}\text { Achromobacter sp. } \\
\text { ('Mima') }\end{array}$ & 21 & 0 & 21 & 0 & 21 & $\mathbf{0}$ & 21 & $\mathbf{0}$ \\
\hline Moraxella & $\mathbf{1}$ & $\mathbf{0}$ & 1 & 0 & 1 & 0 & 1 & 0 \\
\hline Alcaligenes & 4 & 0 & 4 & 1 & $\mathbf{3}$ & 2 & 2 & 0 \\
\hline Vibrio & $\mathbf{3}$ & 0 & $\mathbf{8}$ & $\mathbf{0}$ & $\mathbf{B}$ & $\mathbf{0}$ & $\mathbf{3}$ & $\mathbf{0}$ \\
\hline Xanthomonas & 2 & 0 & 2 & $\mathbf{0}$ & 2 & $\mathbf{0}$ & 2 & 0 \\
\hline Aeromonas & 4 & 4 & $\mathbf{0}$ & 8 & 1 & 2 & 2 & 0 \\
\hline Pseudomonas & 54 & 50 & 4 & 49 & 5 & 53 & 1 & 0 \\
\hline Unidentified & 10 & $\mathbf{0}$ & 10 & $\mathbf{0}$ & 10 & $\mathbf{0}$ & 10 & $\mathbf{0}$ \\
\hline
\end{tabular}

Moller's technique. Tests by this method were positive with all but four of the pseudomonads, but with five strains of Pseudomonas fuorescens, one of $\boldsymbol{P}$. graveolens and four of the unclassified strains, the positive results were only obtained at $22^{\circ}$. Negative results were given by one strain of $\boldsymbol{P}$. fluorescens, by the strains of $\boldsymbol{P}$. ovalis and $\boldsymbol{P}$. mucidolens, and by one unclassified strain.

Among other genera and groups positive results were given by the four strains of Aeromonas, by the majority of salmonellas and by over half the strains of Cloaca.

The Manchester technique. By this method all but five of the pseudomonads were positive; those which gave negative results were one strain each of Pseudomonas aeruginosa, $\boldsymbol{P}$. fluorescens, $\boldsymbol{P}$. ovalis, $\boldsymbol{P}$. mucidolens and one unclassified strain. The strains of $\boldsymbol{P}$. aeruginosa and $\boldsymbol{P}$. fluorescens gave positive results by Møller's method, but the other three were negative by both techniques. 
Among other genera and groups positive results were similarly distributed to those given by Møller's method, except that the majority of salmonellas were negative and three strains of Achromobacter anitratus (Bacterium anitratum), and one each of Escherichia and of Alcaligenes were positive. The discrepancy between the results of the two qualitative techniques with salmonellas was only apparent after $24 \mathrm{hr}$. incubation. The majority of these strains produced an alkaline reaction in the medium used for the Manchester technique when incubation was prolonged for another day.

The quantitative technique. Among the pseudomonads all but one strain, Pseudomonas mucidolens, broke down more than $50 \%$ of the arginine in $2 \mathrm{hr}$. Among other genera and groups, positive results were also given by two of the aeromonads, and by two strains in the Alcaligenes group. It is of interest that both the positive Alcaligenes strains were polar flagellate, whereas the two negative strains were peritrichate.

When complete breakdown of arginine under the conditions of test is taken as the dividing line between positive and negative results, the test becomes more specific, but less sensitive: 49 of the 54 pseudomonads were positive by this criterion, the exception being two strains of Pseudomonas fluorescens, and one strain each of $P$. aeruginosa, $P$. ovalis and $P$. mucidolens. None of the organisms from other genera and groups brought about complete arginine breakdown.

Unidentified organisms. Ten strains gave negative results by the tests for arginine breakdown. Six of them were non-motile, non-pigment producing rods which were either non-fermenting or glucose-fermenting only. They were either negative or weakly positive by the oxidase and cytochrome-oxidase tests, and differed from pseudomonads in several of their other morphological, biochemical or cultural characteristics. They could not be assigned to the 'Mima' or 'Bacterium anitratum' groups, and their identity remains in doubt.

Two of the other unidentified strains were also non-motile and fermented a number of carbohydrates without the production of gas; one of them was penicillin sensitive and the other possessed a powerful urease. Once again it was not possible to allocate them with certainty to a particular genus on their general characteristics.

The remaining two unidentified strains were slim, polar flagellate, motile rods. The first produced a yellow non-diffusible pigment, was a facultative anaerobe, gave a negative result by Kovacs' oxidase test after $15 \mathrm{sec}$., was catalase-negative, and sensitive to Erythromycin. The second strain was nonfermenting, non-pigment producing, oxidase-negative at 15 sec., very weakly catalase-positive and Erythromycin sensitive. Both these strains resembled pseudomonads in their morphology and in some of their biochemical and cultural characteristics. The first of them, however, differed in a number of respects and cannot satisfactorily be included in the genus Pseudomonas. The taxonomic relationship of the second strain to Pseudomonas is closer, but the combination of poor catalase activity, negative Kovacs' oxidase reaction, and Erythromycin sensitivity set it apart from the other nonpigmented pseudomonads that we studied. 


\section{DISCUSSION}

The results presented here show that nearly all the pseudomonads tested were able to break down arginine more rapidly than most other Gram-negative rod-shaped organisms, and suggest that this characteristic may prove to be a useful differential feature. It is important to stress that the distinction between pseudomonads and some other bacteria, e.g. Escherichia, in this respect is essentially quantitative and that the specificity of the techniques we have described depends on careful attention to the conditions and duration of the tests.

The quantitative technique proved to be the most satisfactory, because the density of the bacterial suspension and the reaction and composition of the suspending medium could be controlled, while reducing conditions were rapidly established in the reaction mixture. The two qualitative techniques, on the other hand, although giving reasonably similar results, were influenced by a number of uncontrolled factors such as the rate and amount of growth of the organisms, the speed with which oxygen was consumed, and the occurrence of glucose fermentation. These variables account for the somewhat lower specificity of the qualitative tests in detecting those strains with the greatest activity against arginine.

No detailed studies were made to determine the route of breakdown of arginine by the organisms which gave positive results in our tests. It is known that bacteria may act on this substrate either by means of the arginine dihydrolase system (Hills, 1940; Knivett, 1952; Slade \& Slamp, 1952) or by means of a decarboxylase. In the dihydrolase system the end products of the breakdown of one molecule of arginine are one molecule of ornithine, two molecules of $\mathrm{NH}_{3}$ and one of $\mathrm{CO}_{2}$. This leads to the development of an alkaline reaction and detectable concentrations of ammonia in lightly buffered argininecontaining media such as those used in our qualitative tests. An alkaline reaction may also result from the production of basic amines by decarboxylase activity, but Møller (1955) has shown that this change occurs slowly in his medium, and that a rapid indicator change and the production of $\mathbf{N H}_{3}$ is the result of arginine dihydrolase activity. All the organisms in our series which gave a positive result at $24 \mathrm{hr}$. by this technique also showed ammonia production, and thus appear to have possessed the arginine dihydrolase system. Added support for this conclusion has been provided by the direct demonstration of arginine dihydrolase activity in a pseudomonad by Slade, Doughty \& Slamp (1954) and also in our strain of Pseudomonas viscosa (Shoesmith \& Sherris, unpublished observation).

It is of interest that the four strains, other than pseudomonads, which broke down more than $50 \%$ of the arginine in the quantitative test were polarly flagellate. The strains classified as Aeromonas (Kluyver \& van Niel, 1936) come from a group of organisms which have, in the past, sometimes been included in the genus Pseudomonas (Bergey's Manual, 1948), but are considered by more recent workers to merit a separate genus among the Pseudomonadaceae on account of their fermentative capacity and ability to 
produce 2:3-butanediol from glucose (Stanier, 1943; Miles \& Miles, 1951). Our observations show that they have another characteristic in common with pseudomonads in addition to being polarly flagellate. The two positive strains in the Alcaligenes group were also polarly flagellate, and thus conformed to the characteristics of Vibrio alkaligenes (see Nyberg, 1935) except that they did not now show any curvature of the rod, and presented few distinguishing features from non-pigment-producing pseudomonads. The possession of polar flagella was not, however, completely correlated with rapid arginine breakdown, as one strain of $V$. cholerae and two of the $\mathrm{El}$ Tor vibrio were quite inactive in this respect.

The identification of pseudomonads in practice may, as Gaby \& Hadley (1957) have pointed out, present difficulties with strains not producing pigment. The tests for arginine breakdown that we have used may prove to have some practical value in identifying such strains. The qualitative techniques are simple to perform and a positive result after $24 \mathrm{hr}$. incubation with a strain which does not produce acid from any sugar, or only from glucose, strongly indicates that the organism is a pseudomonad. Of the two methods, that of Møller appears to be a little more specific than the Manchester technique in this respect. The quantitative test is the most specific, and, in our experience, complete arginine breakdown under the conditions described is produced only by members of the genus Pseudomonas.

One of us (J.G.S.) was in receipt of an Agricultural Research Council Junior Fellowship.

\section{REFERENCES}

Bergey's Manual of Determinative Bacteriology (1948). 6th ed. Edited by R. S. Breed, E. G. D. Murray \& A. P. Hitchens. London: Baillière, Tindall and Cox.

Christensen, W. B. (1946). Urea decomposition as a means of differentiating Proteus and Paracolon cultures from each other and from Salmonella and Shigella types. J. Bact. 52, 461.

Gaby, W. L. \& Hadley, C. (1957). Practical laboratory test for the identification of Pseudomonas aeruginosa. J. Bact. 74, 356.

Gordon, J. \& McLEod, J. W. (1928). The practical application of the direct oxidase reaction in bacteriology. J. Path. Bact. 31, 185.

Hruss, G. M. (1940). Ammonia production by pathogenic bacteria. Biochem. $J$. 34, 1057.

Kuuvver, A. J. \& van Niel, C. B. (1936). Prospects for a natural system of classification of bacteria. Zbl. Bakt. (2 Abt.), 94, 369.

KNIveTr, V. A. (1952). Citrulline as an intermediate in the breakdown of arginine by Streptococcus faecalis. Biochem. J. 50, xxx.

Kovacs, N. (1956). Identification of Pseudomonas pyocyanea by the oxidase reaction. Nature, Lond. 178, 703.

MrLes, E. M. \& Mrres, A. A. (1951). The identity of Proteus hydrophilus Bergey et al. and Proteus melanovogenes Miles \& Halnan, and their relation to the genus Aeromonas Kluyver \& van Niel. J. gen. Microbiol. 5, 298.

Møller, V. (1955). Simplified tests for some amino acid decarboxylases and for the arginine dihydrolase system. Acta path. microbiol. scand. 36, 158.

Nyberg, C. (1935). Bacillus faecalis alcaligenes Petruschky. Zbl. Bakt. (1 Abt.) 133, 443. 
Rosenberg, H., Ennor, A. H. \& Morrison, J. F. (1956). The estimation of arginine. Biochem. J. 63, 153.

Sherris, J. C., Preston, N. W. \& Shoesmith, J. G. (1957). The influence of oxygen and arginine on the motility of a strain of Pseudomonas sp. J. gen. Microbiol. 16,86 .

Slade, H. D., DoughTY, C. C. \& Slamp, W. C. (1954). The synthesis of high-energy phosphate in the citrulline ureidase reaction by soluble enzymes of Pseudomonas. Arch. Biochem. Biophys. 48, 338.

Slade, H. D. \& Slamp, W. C. (1952). The formation of arginine dihydrolase by streptococci and some properties of the enzyme system. J. Bact. 64, 455.

Stanier, R. Y. (1948). A note on the taxonomy of Proteus hydrophilus. J. Bact. 46, 213.

(Received 23 March 1959) 